Viso - Cadernos de estética aplicada Revista eletrônica de estética

ISSN 1981-4062

No 10 , jan-dez/2011

http://www.revistaviso.com.br/

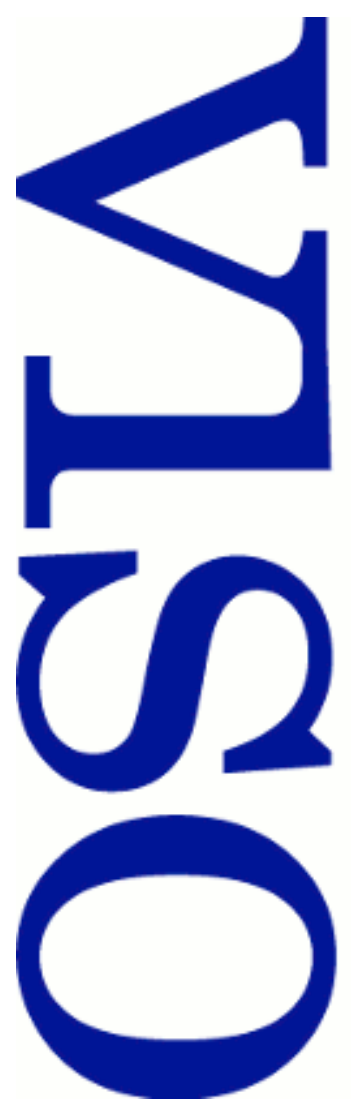

\title{
Depois do filme, de Aderbal Freire-Filho Patrick Pessoa
}

Universidade Federal Fluminense (UFF) Niterói, Brasil 


\section{RESUMO}

Depois do filme, de Aderbal Freire-Filho

O artigo apresenta uma crítica imanente da peça "Depois do filme", de Aderbal FreireFilho, estabelecendo relações entre os elementos da encenação e as ideias de Paul Lafargue, dos pré-socráticos e de Machado de Assis.

Palavras-chave: crítica teatral - Aderbal Freire-Filho - Paul Lafargue - Machado de Assis

\section{ABSTRACT}

\section{Aderbal Freire-Filho's After the Film}

he article presents an analysis of the play "After the film", written, directed and performed by Aderbal Freire-Filho. It shows possible relations between the play and some ideas by Paul Lafargue, the pre-socratic philosophers and Machado de Assis.

Keywords: Theater Criticism - Aderbal Freire-Filho - Paul Lafargue - Machado de Assis 
PESSOA, P. "Depois do filme, de Aderbal Freire-Filho". In: Viso: Cadernos de estética aplicada, v. V, n. 10 (2011), pp. 1-10.

DOI: 10.22409/1981-4062/v10i/107

Aprovado: 31.10.2011. Publicado: 19.04.2012.

(C) 2012 Patrick Pessoa. Esse documento é distribuído nos termos da licença Creative Commons Atribuição-NãoComercial 4.0 Internacional (CC-BY-NC), que permite, exceto para fins comerciais, copiar e redistribuir o material em qualquer formato ou meio, bem como remixá-lo, transformá-lo ou criar a partir dele, desde que seja dado o devido crédito e indicada a licença sob a qual ele foi originalmente publicado.

Licença: http://creativecommons.org/licenses/by-nc/4.0/deed.pt_BR

Accepted: 31.10.2011. Published: 19.04.2012.

(C) 2012 Patrick Pessoa. This document is distributed under the terms of a Creative Commons Attribution-NonCommercial 4.0 International license (CC-BY-NC) which allows, except for commercial purposes, to copy and redistribute the material in any medium or format and to remix, transform, and build upon the material, provided the original work is properly cited and states its license.

License: http://creativecommons.org/licenses/by-nc/4.0/ 
No programa da peça Depois do filme, escrita e dirigida por Aderbal Freire-Filho, que além de tudo é o único ator em cena, ele apresenta galhardamente "14 razões para não escrever um texto para este programa". Contra essas catorze razões, dentre as quais de fato todas são muito convincentes ou, conforme o ponto de vista, estapafúrdias - a escolha dependerá do humor do espectador, que é convidado a participar do jogo proposto por Aderbal desde a entrada na bela sala do recém-inaugurado Teatro Poeirinha -, eu apresento três razões, estas sim irrefutáveis: 1) o programa contém a epígrafe da peça, sem a qual não se compreendem nem a sua gênese nem o seu alcance; 2) define o seu princípio formal como "cinema falado", desdobramento fecundo dos "romances-em-cena" dirigidos por Aderbal nas duas últimas décadas; 3) apresenta a mesma dialética entre negação teórica ("14 razões para não escrever...") e afirmação prática da existência (afinal de contas, o programa foi escrito) que estrutura o percurso existencial do protagonista Ulisses, cuja odisséia é menos a de seu xará grego do que a de um antecessor tão carioca quanto ele, o defunto autor Brás Cubas.

\title{
Depois do filme: resposta a Paul Lafargue
}

\begin{abstract}
Sadio de corpo e de espírito, eu me mato antes que a impiedosa velhice, que me arrebata um a um os prazeres e as alegrias da existência e me despoja de minhas forças físicas e intelectuais, paralise minha energia e enfraqueça minha vontade e faça de mim uma carga para mim e para os outros. Há muitos anos eu me prometi não ultrapassar os 70 anos; eu determinei ainda a época do ano para a minha partida da vida e preparei o modo de execução da minha resolução: uma injeção hipodérmica de ácido cianídrico.
\end{abstract}

Essa passagem, que já seria inquietante mesmo que tivesse sido escrita por um personagem de ficção, ganha ares de pregação moral quando descobrimos que foi extraída "do testamento de Paul Lafargue, autor de $O$ direito à preguiça, que se suicidou aos 69 anos, junto com sua esposa Laura, filha de Karl Marx".

Aderbal Freire-Filho fez 70 anos em maio de 2011, mês em que estreou sua peça. Esse dado biográfico, por si só, seria suficiente para pensar Depois do filme como uma resposta a Paul Lafargue. Se Aderbal e Lafargue têm em comum o fato de jamais terem se dado o direito à preguiça, o que para este representou a inexorabilidade do suicídio, para aquele marcou uma nova fase produtiva e a assunção de um novo risco: ser ator em um monólogo. Não, isso seria ainda pouco. Depois do filme, explica Aderbal no programa do espetáculo, "não é um monólogo, podia ser uma superprodução, uma peça de grande elenco. Como quase abandonei o ofício de ator e tenho passado a vida ensaiando do 'lado de fora', decidi me vingar logo fazendo o papel de muitos".

Aos 70 anos, diz Aderbal ao amigo Lafargue, a hora é de vestir as fantasias, colocar as máscaras e se divertir com a sabedoria de que todas elas, até mesmo a de velho, são transitórias. A hora, mais do que nunca, é de nadar de fora para dentro do palco, e não de dentro para fora! 
Mas Aderbal não é Ulisses. A confusão entre autor/ator e personagem deve ser evitada, ainda que qualquer purismo nessa questão, sobretudo depois de Brecht, soe sempre pueril. Nem identificação plena entre ator e personagem, base para um ilusionismo alienante, nem distanciamento absoluto, pai do cinismo e mãe do esvaziamento dramático contemporâneos. Uma mistura, imprecisa e delicada, de ambos. Mais que mistura. Oscilação. Entre um pólo e outro. Entre.

E é oscilando, literalmente tremendo, que Ulisses entra em cena, em seu carro "todo fodido", pensando em suicídio em pleno vão central da ponte Rio-Niterói. Sim, se o tema lafarguiano do suicídio não é central para o autor-ator-diretor Aderbal, sem dúvida o é para seu personagem, que comunica a todos com quem se encontra ao longo da peça a vontade de acabar com a própria vida. Sua fragilidade é ressaltada desde suas primeiras palavras, amplificadas pelo equilíbrio precário com que o ator tem de atravessar a instável ponte de cadeiras que lhe serve de cenário.

Tal composição cênica, calcada no despojamento de figurinos (de Kika Lopes) e cenários (de Fernando Mello da Costa) e no trabalho de corpo mais instintivo do que olimpicamente treinado de um ator bissexto, deixa claro que a odisséia deste Ulisses não tem a ver com a força dos músculos de aço, nem tampouco com essa outra força homérica que é a da inteligência ou a da técnica infalível. Tem muito mais a ver com uma força, "interior-exterior", como ela é definida em certa altura do espetáculo e que descreve à perfeição o trabalho do ator, que só transparece quando alguém se permite levar a fragilidade ao limite, quando alguém se permite realmente uma auto-exposição e não teme a queda (no ridículo). Para ser o homem que estava lá, e não aquele homem em preto e branco do filme dos Coen que se parece com tantos atores do teatro contemporâneo, para ser o homem que verdadeiramente estava lá, no lugar onde brota o desejo de viver mil vidas - por que nos contentaríamos com menos do que tudo? -, é preciso ser um colosso de fragilidade.

A cena inicial, a da travessia da ponte Rio-Niterói, torna-se épica por isso: dali em diante, todo o equilíbrio vai ser delicado. Quando o equilíbrio deixa de ser uma questão, e alguém se sente "seguro", é porque já se tornou pedra. Isso é justo o que o suicida Lafargue não foi capaz de entender. O enrijecimento lembra a face da morte. Seu contraponto: os gestos, os rostos, os timbres do ator que se deixa atravessar por um movimento imprevisível e incontrolável. $O$ ator: alguém que se esforça todo para registrar a coincidência, sempre milagrosa, entre a idéia e o afeto. Milagrosa e passageira, como o descanso de Sísifo, esse ancestral de Ulisses. Mas a própria luta em direção aos cimos já é suficiente para preencher um coração humano.

\section{Cinema falado}

Ainda uma vez, voltemos ao "inútil" programa de Depois do filme: "Ulisses, saído dos mares do filme Juventude, de Domingos Oliveira, está de volta a sua ilha, mas nem seu 
cachorro o reconhece. Pensa que é Burt Lancaster, de Enigma de uma vida, e tenta nadar (The swimmer), enquanto seus sonhos naufragam. Tem muitos sonhos e pouco tempo".

Roberto Rossellini costumava dizer que, no dia em que não tivesse mais dinheiro para realizar os seus filmes, passaria a escrevê-los. Domingos Oliveira, que escreveu e dirigiu Juventude, o filme em que o Ulisses de Aderbal aparece pela primeira vez, obliquamente imita o exemplo do mestre italiano, escrevendo filmes tão falados que barateiam a produção a ponto de miraculosamente torná-la possível. Seria tentador construir uma analogia entre o modo como Domingos viabiliza o seu cinema aproximando-o do teatro mesmo que não negligenciemos o fato de que suas técnicas de enquadramento e montagem são genuinamente cinematográficas - e o modo como Aderbal vitaliza o seu teatro aproximando-o do cinema, mas por ora me concentrarei apenas no conceito de "cinema falado" como aparece em Depois do filme.

Em sua peça, Aderbal imita e subverte o procedimento teatral contemporâneo de dizer não apenas as falas dos personagens, mas também as rubricas sempre um tanto literárias - "um romance", segundo definição do próprio Aderbal, "nada mais é do que uma peça teatral em que há mais rubricas do que diálogos" - com que alguns dramaturgos pretendem roubar o seu quinhão do trabalho do diretor. Mas ele transfigura as rubricas teatrais em cabeçalhos de um roteiro cinematográfico.; "Cena 1. Exterior. Noite. Ponte Rio-Niterói".

Essa transfiguração do lugar-comum, no entanto, não deve ser lida como mero procedimento formal. Supondo que a beleza do teatro está em fazer com que cada apresentação seja, para o ator, única e inimitável, a beleza do cinema está em fazer com que cada espectador possa experimentar alegria análoga à do ator. Ainda que todas as cópias de um filme sejam idênticas, cada projeção será sempre única para seus espectadores. O crítico, que será o "espectador ideal" na medida em que for capaz de assumir a co-autoria daquilo que critica, é também, como o ator e o músico, um intérprete. Por isso, o crítico precisa deixar-se guiar pelo exemplo do ator, cuja arte de interpretação pressupõe uma familiaridade com o texto (da peça) que nenhum crítico jamais há de alcançar. Afinal, na prática de um ofício, a crítica, que exige a interpretação de um número infinitamente maior de peças do que aquelas em que um ator poderia trabalhar no mesmo espaço de tempo - interpretar, para o crítico, significa desmontar e remontar um espetáculo nessa outra forma de poesia que é a prosa crítica -, quem é que pode concorrer com o ator, que tem o privilégio inigualável de montar o mesmo espetáculo quase diariamente ao longo de no mínimo seis meses (aí somados ensaios e temporada)?

Seguindo a lógica dessa comparação, todo diretor teatral encontra-se a meio caminho entre o crítico e o ator, entre a interpretação filosófico-literária de uma peça e a sua materialização gestual. Neste sentido, é possível compreender ainda sob outro prisma a vingança de Aderbal: nadar de fora para dentro do palco é, para ele, não apenas fazer a 
travessia entre o diretor e o ator, mas também aquela entre o crítico e o ator. Se Depois do filme começa com Ulisses no meio da ponte, e não em algum de seus extremos, Rio ou Niterói, é porque Aderbal quer deixar claro que essa travessia nunca é completa. Com ou sem pedras, estamos sempre no meio do caminho.

O modo como, neste trabalho, Aderbal está a meio caminho entre o crítico/diretor e o ator é absolutamente singular. Se toda história deixa marcas mais ou menos conscientes em quem a viveu (sendo este talvez o tema central do filme Juventude, de Domingos de Oliveira) - que percepção distante da realidade é esta nossa percepção cotidiana de que o passado passa! -, a história de Aderbal como diretor/crítico amplifica radicalmente a autorreflexividade inerente ao seu espetáculo. Se é possível sonhar um ator apenas instintivo, o sonho torna-se pesadelo quando imaginamos um diretor tiranicamente movido apenas por suas "intuições".

Em Depois do filme, espetáculo de um diretor mais iluminista do que iluminado, capaz de justificar argumentativamente cada uma de suas opções, a autorreflexividade característica de toda obra de arte digna deste nome ganha corpo como um entrelaçamento entre a forma teatral-cinematográfica e o teor filosófico-existencial.

Do ponto de vista estritamente formal, o "cinema-falado" de Aderbal Ihe permite potencializar teatralmente o uso de suas rubricas - é reconfortante ver uma peça que nos faz enxergar travellings, panorâmicas e close-ups, a princípio inexistentes na linguagem teatral, valendo-se apenas de luz, cenário e atuação, sem apelar para o clichê contemporâneo daquelas projeções do material filmado pelos próprios atores em cena e assim ampliar o alcance das experiências iniciadas em seus romances-em-cena. Tanto no "cinema falado" quanto nos "romances-em-cena", Aderbal flerta com a alquimia, buscando o equilíbrio entre drama e narração, identificação e distanciamento, fruição e crítica. Esse equilíbrio é a pedra filosofal do teatro contemporâneo.

Já do ponto de vista existencial-filosófico, a idéia de "cinema falado" permite que Aderbal refute Paul Lafargue por um caminho distinto do que discuti na primeira parte deste texto. Se Lafargue se matou por não suportar que a existência humana seja marcada por envelhecimento e morte, isto é, pela transitoriedade, Aderbal propõe que o cinema nos eterniza. Mesmo quando os velhos cinemas, como o Cine Vitoria que Ulisses revisita em dado momento do espetáculo, não existem mais, os filmes bons continuam a passar numa sala de cinema eterna, encantada, que só obtusos homens da lei não são capazes de enxergar. Que o teatro possa ser esse cinema, muito mais do que os cinemas propriamente ditos, inteiramente submetidos ao império da mercadoria, eis a aposta aderbaldiana - o próprio nome do teatro em que montou o seu espetáculo, "Poeira", uma antiga designação para salas de cinema que não existem mais, corrobora essa afirmação. 


\section{De Ulisses a Brás Cubas}

Ulisses, perto dos 70 anos, passa a peça inteira dizendo que vai se matar, e apresentando àqueles com que se encontra as razões para o suicídio: razões que, jocosamente ou não, ao estilo de Paul Lafargue, têm a pretensão filosófica de serem universais.

Dentre essas razões, a mais repetida diz respeito à falta de tempo para viver todas as vidas que poderia viver, ao excesso de possibilidades existenciais irrealizadas (e irrealizáveis). A certa altura da peça, em conversa com a boliviana vendedora de pulseiras, Ulisses lhe diz:

Quero me matar para me livrar da agonia de querer fazer o que não fiz e agora não dá mais tempo, pela falta de tempo. Os velhos querem tanto como os jovens, aprender música, tocar, namorar mulheres de peitos bonitos, ganhar dinheiro, viajar, estudar filosofia, nadar bem, beber todos os vinhos, e sobretudo ter projetos, muitos projetos. Para umas coisas eles não têm mais condições físicas, para outras não dá mais tempo. É terrível.

Mais adiante, em conversa com a moça dos peitos bonitos, ele prossegue: "Já não agüento mais ficar esperando, não consigo fazer mais nada com medo de morrer, de começar e não dar tempo de terminar, é paralisante. Então quero acabar logo, pá, fim".

Essa cantilena melancólica, entoada ao longo de toda peça, guarda uma relação subterrânea com a "teoria das coincidências" defendida por Ulisses num banco da praça Nossa Senhora da Paz. Segundo ele diz a algumas crianças e babás desavisadas,

tudo é coincidência. O mundo não é formado da condensação de água, como queria Tales de Mileto, o mundo é formado da condensação de coincidências. Anaximandro, que também era de Mileto, discordava de Tales e dizia que tudo não era água, mas que tudo era o llimitado. Ouviu o galo cantar sem saber onde. O llimitado é o caldeirão onde as bruxas mexem as coincidências. Eu anoto as coincidências que vejo. É um método igual ao dos gregos, da contemplação. Já tenho mais de duas mil coincidências anotadas e ainda não consegui dar com os elos, as engrenagens, os mecanismos, nem acho que vou ter tempo.

Seu suicídio teria duas razões complementares: a impossibilidade de terminar o que quer que seja - alguém já disse que a vida é um poema épico: já sempre chegamos no meio da história e saímos antes de sua conclusão - e a impossibilidade de encontrar o "Grande Mecanismo" que rege a nossa história. Diante dessas duas impossibilidades, que não foram superadas nem mesmo pela visita ao eminente doutor Mira y Lopez, Ulisses se revolta: "por que a vida é assim? Por que não tão é clara e infinita como deveria ser?"

Essa contraposição entre o ser e o dever ser, a realidade e o ideal, a descoberta do absurdo (como descoberta da finitude biológica e do inacabamento constitutivo de todos os projetos humanos) e um anseio desmedido pela ordem que justificaria todas as ações 
humanas é o que dilacera Ulisses. Neste ponto, Aderbal aperfeiçoou o texto do filme de Domingos, que deu um desnecessário fundamento (melo)dramático à questão quando introduziu o tema da doença da filha. Em Depois do filme, Paloma, a filha de Ulisses, está curada, mas sua felicidade "sem Sartre" não é menos doente - ao menos sob a ótica do pai - que sua anterior infelicidade. Ambas são ontologica e não apenas circunstancialmente absurdas. Se a infelicidade (a morte) é sempre imerecida, a felicidade (a vida) também o é. Esta é a coincidência que Ulisses não pode suportar.

Diante de uma descoberta semelhante, realizada diante do leito de morte da própria mãe, roída pelo câncer, a mais terrível das doenças na medida em que atua como a personificação mesma do absurdo, Brás Cubas, um antecessor da revolta de Ulisses, queda-se com a consciência boquiaberta: "Quê? uma criatura tão dócil, tão meiga, tão santa, que nunca jamais fizera verter uma lágrima de desgosto, mãe carinhosa, esposa imaculada, era força que morresse assim trateada, mordida pelo dente tenaz de uma doença sem misericórdia? Confesso que tudo aquilo me pareceu obscuro, incongruente, insano...". Face à insanidade da vida, Brás Cubas posiciona-se: se a Natureza, nossa mãe, é também nossa inimiga, e só nos dá a vida apenas para poder nos dar a morte, não sendo (unívoca) como deveria ser, então me recuso a compactuar com ela. Se toda realização tende à irremediável corrosão pelo tempo, o único antídoto é não realizar nada - ou matar-se.

O apego a essa paralisante resposta é o que nos permite compreender a sua "tez cadavérica" ao longo de todo o romance, em que ele narra o seu suicídio vivido. Como "defunto autor" de sua existência, a partir da descoberta do absurdo Brás viveu paralisado como um morto. Um defunto cujo único prazer era escarnecer da azáfama sem sentido dos vivos. Assim compreende-se o fecho de ouro de seu romance: depois de se comprazer em descrever tudo o que não fez e não foi, Brás ainda se gaba por ter saído da vida com um pequeno saldo, o de não ter tido filhos, não haver transmitido a nenhuma criatura o legado de nossa miséria. Mas o narrador Brás Cubas termina o seu romance sem perceber algo que decerto não escapou ao autor Machado de Assis e a seus futuros leitores: se ter filhos não é de forma alguma o único modo de transmitir a outra(s) criatura(s) o legado de nossa miséria, Brás Cubas acabou por agir contra as suas intenções declaradas ao redigir as suas memórias póstumas. Na prática, o seu livro é o seu legado. Contra todas as mais razoáveis razões, a vida, absurdamente, ainda uma vez triunfou. Negá-la artisticamente é uma das formas mais elevadas de, ao fim e ao cabo, afirmá-la.

O que vale para Brás Cubas vale ainda mais radicalmente para o Ulisses de Aderbal. Se toda a sua odisséia ao longo da peça visa ao suicídio e à sua fundamentação filosófica, seu fracasso é o seu maior sucesso. O tratado sobre a inexorabilidade lafargueana do suicídio que é o sumo da narrativa de Ulisses é subvertido no ato mesmo de encená-la, em que a alegria do ator Aderbal por viver mil vidas - e que se dane que sejam absurdas como a de uma mulher que briga com o marido errado! - deixa para trás a melancolia de 
um personagem que professa uma filosofia mais do que duvidosa. Por isso, quando, ao cabo de suas peripécias, Ulisses joga com valentia o seu carro todo fodido contra uma árvore e com Valentín escapa ileso da morte certa, já não resta mais nada a dizer.

E o resto seria mesmo silêncio, se não fôssemos ainda brindados com uma última imagem épica do mar, projetada no telão do teatro. Do mar com todo o seu som e a sua fúria, mas também com toda a sua calma e a sua beleza caymmianas. Se, como queria Tales de Mileto, "tudo é água", e, como queria seu discípulo Anaximandro, os limites de cada vida só se tornam visíveis sob o pano de fundo deste llimitado que é a Vida com $\mathrm{V}$ maiúsculo, que naturalmente não exclui a morte, o mar, velha metáfora para a dialética de vida e morte, eternidade e tempo, fala a língua de um outro grego da época áurea. Em um bilhete deixado para Ulisses, com uma antecedência talvez excessiva, Heráclito escreveu: "Aos homens, nem sempre é melhor suceder tudo o que desejam".

* Patrick Pessoa é professor adjunto do Departamento de Filosofia da UFF. 